Revista Mídia e Cotidiano

Artigo Seção Temática

Volume 12, Número 1, abril de 2018

Submetido em: 28/02/2018

Aprovado em: 28/04/2018

\title{
MIDIATIVISMO EM ANÁLISE: contribuições de uma pesquisa de doutorado ${ }^{1}$
}

\section{MEDIA ACTIVISM UNDER ANALYSIS: contributions of a doctoral research}

\author{
Antonio Augusto BRAIGHI ${ }^{2}$
}

\section{Resumo:}

Apresenta-se aqui a síntese de uma tese de doutorado que teve como propósito, no intuito de estabelecer parâmetros para uma análise do discurso midiativista, investigar as condições de produção discursiva do Mídia Ninja - referência em tal segmento de atuação no Brasil, buscando compreender o lugar que este coletivo ocupa no regime midiático contemporâneo. $\mathrm{O}$ estudo, que culminou em mais de 600 páginas de diagnóstico, teve como recorte transmissões simultâneas de protestos (290 vídeos - 97h) e, para tanto, empreendeu a circunscrição estrutural do dispositivo técnico de produção, a apreciação crítica do dispositivo comunicacional e enunciativo além do exame da dinâmica interacional do mencionado veículo. Evidencia-se no presente trabalho então particularidades da pesquisa e os principais resultados obtidos com a mesma.

Palavras-chave: Midiativismo; Mídia Ninja; Análise do Discurso; Transmissões Simultâneas

\begin{abstract}
:
Here we present the synthesis of a doctoral thesis (in order to establish parameters for an analysis of the discourse Media Activist) whose purpose was to investigate the conditions of discursive production of the Media Ninja - reference in such segment in Brazil, seeking to understand the place that this collective occupies in the contemporary mediatic situation. The study, culminating in more than 600 pages of diagnosis, had as a cutout simultaneous broadcasts of protests (290 videos - 97h). For this, it was undertaken the structural division of the technical device of production, the critical appreciation of the communicational and enunciative device and examining the interactional dynamics of said vehicle. In this work, we show the particularities of the research and the main results obtained with it.
\end{abstract}

Keywords: Media Activism; Mídia Ninja; Discourse Analysis; Simultaneous Broadcasts.

\footnotetext{
${ }^{1}$ Trabalho apresentado inicialmente no GP Comunicação para a Cidadania, XVII Encontro dos Grupos de Pesquisas em Comunicação, evento componente do $40^{\circ}$ Congresso Brasileiro de Ciências da Comunicação. Aqui revisto e editado.

${ }^{2}$ Doutor em Linguística do Texto e do Discurso (Estudos Linguísticos - FALE/UFMG) e professor do CEFET-MG.
} 


\section{míDiA

\section{INTRODUÇÃO ${ }^{3}$}

A internet parece inaugurar uma série de fenômenos. Mas, apenas parece mesmo. É inegável a linha tênue que tem marcado o processo de afetação mútua real-virtual, conformando uma "virtualização" da vida social como a conhecíamos. "Os espaços se metamorfoseiam e se bifurcam a nossos pés, forçando-nos à heterogênese", já impetrava Pierre Lévy (2003, p. 23). É nesse contexto que damos à grande rede os créditos pela (re)incidência de alguns fenômenos, tais como o midiativismo.

Todavia, esse neologismo em certa medida é considerado por muitos tão somente a mídia alternativa rediviva, encorpada com o potencial web. Não concordamos que o mundo digital on-line tenha tido seiva para tanto, mas também deixamos de pactuar com a ideia de que os conceitos sejam iguais e que o primeiro não tenha as suas idiossincrasias. Foi assim que decidimos nos embrenhar nas contrariedades e complexidades inerentes ao discurso midiativista.

Falamos aqui em primeira pessoa, ao menos nesse início de artigo, dado que apresentamos os resultados de uma pesquisa de doutorado conduzida pelo autor do presente artigo - e tragamos a voz para o plural para convidar o leitor a seguir conosco o caminho que trilhamos em nossa tese. Para essa, tivemos como primeira demanda, para nos projetar na seara que almejávamos compreender, tomar uma parte para que essa nos servisse de referencial.

Foi assim que o Mídia Ninja, de indicador, tornou-se a materialidade do nosso estudo. Mas, por que ele? Ele surgiu em 2011 no Brasil como uma das primeiras iniciativas cidadãs de registro on-line e em tempo real de protestos. Todavia, esse não é o principal motivo; dois anos depois, conforme muitos de nós nos recordamos, o Brasil teve de lidar com diversas manifestações, que levaram milhares de pessoas às ruas de cidades brasileiras, no que ficou conhecido como o movimento das Jornadas de Junho de 2013. Os atos foram marcados pelo grito da crise de representatividade, política e midiática; assim, bandeiras parlamentares e logos de mídias corporativas eram pouco aceitos nas marchas. É nesse contexto que ganha representatividade o supracitado

\footnotetext{
${ }^{3}$ Boa parte do que se apresenta no texto a seguir foi, conforme se infere, retirado ipsis litteris da tese de doutorado a que fazemos referência.
} 


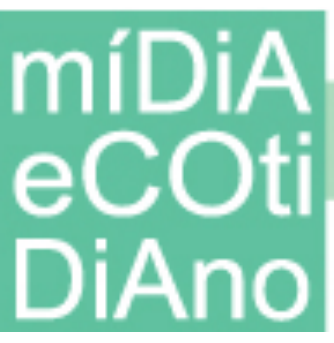

coletivo de comunicação independente que registrava os protestos de perto, ao vivo, pela Internet, pautando, inclusive, os tradicionais veículos de comunicação.

O curso de nosso doutoramento nos permitiu, dada a entrada no programa de pósgraduação em Estudos Linguísticos da UFMG em 2013, observar todo esse fenômeno com muita atenção e cautela. Diversos pesquisadores se puseram a investigar as nuances daquele prodígio social (falamos aqui dos acontecimentos e também das iniciativas midiativistas, não só do Mídia Ninja), trazendo reflexões acerca do cenário. Mas, aquilo tudo se encerraria ali?

Em 2014, durante a Copa do Mundo de Futebol, mais uma vez os Ninjas estavam nas ruas - período que representou o recorte de exame de nossa pesquisa, no intuito de colocar à prova, inclusive, muitas das perspectivas evidenciadas um ano antes. Dado o preâmbulo, o objetivo do trabalho foi o de descrever e analisar as condições de produção do discurso do Mídia Ninja, buscando compreender o lugar que o coletivo ocupa no regime discursivo midiático que se tem na contemporaneidade.

Importante registrar que se fala na tese exclusivamente das transmissões simultâneas do Mídia Ninja (vide Tabela 1, a seguir), e não da série de outras investidas que ele gera. Para tanto, empreendeu-se, como intentos específicos, a circunscrição dos aspectos estruturais que compõem o dispositivo técnico de produção do veículo; a descrição e análise do dispositivo comunicacional e enunciativo regular do coletivo; e, por fim, o exame da dinâmica interacional do grupo midiativista com seus receptores/interlocutores na plataforma Twitcasting.

Como mecanismo de apreciação crítica, procedeu-se à Análise do Discurso, mais especificamente ao campo da semiolinguística, buscando aportes que auxiliassem na constituição metodológica. O ferramental, que compreende uma estrutura triparte, avaliou as dimensões técnicas, interacionais, contextuais, verbais-enuncivas-enunciativas, visuais, sonoras, da relação imagem-texto e dos efeitos. 
Tabela 1 - Transmissões analisadas na tese

\begin{tabular}{|l|c|c|c|c|}
\hline Canais & Transmissões & Vídeos & Tempo Total & Tempo Gravado \\
\hline MN & 30 & 163 & $67: 30: 11$ & $34: 10: 24$ \\
\hline MG & 8 & 50 & $13: 32: 57$ & $07: 41: 11$ \\
\hline RJ & 1 & 41 & $02: 36: 19$ & $00: 28: 18$ \\
\hline RS & 5 & 17 & $06: 32: 31$ & $03: 48: 21$ \\
\hline SP & 3 & 19 & $06: 18: 36$ & $05: 52: 59$ \\
\hline Total & $\mathbf{4 7}$ & $\mathbf{2 9 0}$ & $\mathbf{9 6 : 3 0 : 3 4}$ & $\mathbf{5 2 : 0 1 : 1 3}$ \\
\hline
\end{tabular}

Fonte: Elaborado pelo autor.

No entanto, assentou-se na tese também em uma fundamentação teórica que ajudou a refletir histórica e conceitualmente acerca das ocupações pela sociedade das redes e das ruas, bem como de que maneira a mídia e os mecanismos de mediação exercem papel fundamental nessa conjuntura. Após análises, teve-se como resultado uma decomposição detalhada do coletivo, que expõe as principais propriedades dele, e ajuda numa tomada de caracterização diferente daquela que é propagada no senso comum, a apresentar inclusive um conceito acerca do Midiativismo de forma mais precisa - o que era um anseio primário e que nunca perdemos de vista - fruto de uma incursão que trouxe, em mais de 600 páginas, um diagnóstico que foi aqui sintetizado.

\section{FUNDAMENTAÇÃO TEÓRICO-METODOLÓGICA}

$\mathrm{O}$ arranjo de base teórica da tese privilegiou uma investida em torno dos estudos sociológicos (bem amplo) e outra discursiva (focado principalmente nas contribuições das escolas francesas). Acerca da primeira, empreendeu-se de largada um passeio reflexivo pelas nuances das redes, ruas e mídias. A inferência que se fez foi a de que o coletivo que se apresenta como objeto/corpus do estudo tenha emergido a partir de dois movimentos particulares e que foram, não só por isso, trabalhados de modo mais detalhado: o da sociedade em rede e o da sociedade nas ruas. Como pano de fundo e fator motivador de ofício está também a tomada de voz (ou oportunização de espaços para propagação dos brados) por atores sem tantas entradas nas esferas públicas.

Para tanto, procuramos localizar-nos, sobretudo ao falar da sociedade nas ruas, dos levantes populares mais contemporâneos (num detalhado levantamento histórico), 


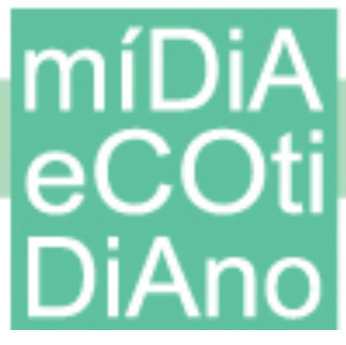

sobretudo dos que marcaram efetivamente a tessitura social no Oriente Médio (com a chamada Primavera Árabe), as investidas ibéricas, norte-americanas e, evidentemente, brasileiras (a saber, as denominadas Jornadas de Junho de 2013). Foram apontadas, então, as particularidades e vicissitudes das novas tecnologias da informação e comunicação nesses contextos, entre outras particularidades.

A proposta foi a de uma inter-relação que permitisse enxergar as minudências nacionais e avaliá-las com mais atenção - principalmente no que ela incorpora do histórico evidenciado. A imersão teórica, afinal, pretendia investigar os contornos sociais e da informação midiática que se dão por influência do (e a influenciar ciclicamente o) Midiativismo, tomando o Mídia Ninja como símbolo, representante proeminente desse movimento, posto o seu inegável reconhecimento público.

Conforme se prevê, Castells $(1999 ; 2013)$ foi então um autor muito caro nessa primeira parte, uma vez que muitas das reflexões desse pesquisador foram tragadas para a seção. Foram colocados em diálogo com ele pensadores que discutiram também os movimentos sociais e/ou os efeitos dos acontecimentos contemporâneos, sobretudo no Brasil (RICCI, 2014; TORET, 2013; MARICATO et al., 2013). No entre-dois, conceitos e reflexões começaram a surgir e deram contornos que marcam posições muito particulares do estudo, tais como as ideias de multidão (HARDT; NEGRI, 2005) e de mídia-multidão (BENTES, 2015) e as características de um neo-jornalismo e as fissuras do modelo industrial midiático (RAMONET, 2013).

Coube à fundamentação teórica também, como importante problema a se resolver, delimitar o que é, enfim, o Midiativismo do ponto de vista conceitual, haja vista a grande profusão terminológica que se encontra ainda hoje. Determinar sobre o que está se falando passa por uma discussão acerca de nomenclaturas que, não sem motivos, ajudam senão a assentar as ideias e a cercar o campo de atuação, ao menos facilita o processo de problematização em torno das perspectivas da comunicação. Mais do que isso, auxilia a pensar sobre o objeto que foi analisado. Assim, a tese conseguiu separar razoavelmente bem os espaços de mídia alternativa (RENDEIRO, 2003; ATTON, 2001), mídia livre (FMML, 2015; MALINI; ANTOUN, 2013), mídia radical (DOWNING, 2004) e Jornalismo de Guerrilha - este para o qual nos alvitramos também a estabelecer uma 


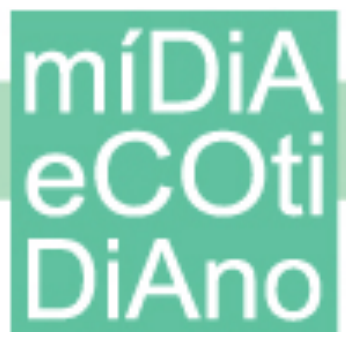

perspectiva conceitual (BRAIGHI et al, 2016) dada a ausência da mesma, frente ao Midiativismo.

Para este último, buscamos definir primeiro o que é ativismo (JORDAN, 2002), para chegarmos, ancorados em conhecimentos prévios acerca da função de mediação evenemencial, na ideia de que a justaposição do binômio mídia + ativismo gera o comportamento de indivíduos que, portadores de uma vontade solidária, empreendem ação direta transgressiva-intencional e veem a suas capacidades de intervenção social localizadas sendo potencializadas, pari passu à implementação da intervenção ativista, por meio de um registro midiático que visa amplificar conhecimento, espraiar informação, marcar presença, empreender resistência e estabelecer estruturas de defesa.

Nesse contexto, ainda que Mídia venha antes no signo linguístico em questão, é ela que serve ao Ativismo. Esse, no entanto, foi motivo de alargada discussão no trabalho doutoral ao qual fazemos remissão. Sabe-se que toda a dinâmica da vida (individual e coletiva) é atualmente e diretamente afetada pelas nuances tecno-web-digitais - que determinam modos de fazer e agir, posto que são dispositivos (na visão foucaultiana). Nesse contexto, fazendo então alusão aos contornos da midiatização (BRAGA, 2006; FAUSTO NETO, 2008), questiona-se: que usos fazemos das novas mídias e de que forma elas influenciam em nossas práticas ordinárias? A resposta é que se tem hoje um bios midiático (que em verdade é a nossa própria sociedade, atravessada pelas nuances midiáticas) em que as interações não precedem do radical tecno (SODRÉ, 2004), imputando novos operadores de inteligibilidade (GOMES, 2006).

Diante de tais concepções, todavia, poder-se-ia dizer que, então, o Midiativismo só existe em razão da estrutura que a tecnologia lhe oferta e que a militância, como campo social, estaria sobreposta pelas características da midiatização? Não concordamos.

Para nós, as ações diretas - esta sim, condição sine qua non para a existência do Midiativismo, pois não se trata de mediação pura e simples - estariam atravessadas pelas peculiaridades do fenômeno exposto, sim. Desse modo, a mídia serve ao ativismo, mas também lhe dá outros contornos, conformando-lhe com suas peculiaridades, transformao. Todavia, o processo é cíclico e se dá não meramente como conceito - o qual nos alvitramos elaborar - mas como prática, que o atualiza a cada nova ação. Como o (midia)ativista assume a condição simultânea de especialista e mediador (RODRIGUES, 
2000) poderia imputar também o tratamento (transfiguração) dos fatos a partir de métricas particulares e estratégias de conformação de sentido - há influência recíproca da tecnologia e da manipulação dela pelo sujeito (BRAIGHI; CÂMARA, 2018), não desprezando o componente principal: a incursão social na causa em tela, qual seja, inscrevendo-se (o midiativista) no fato e no relato.

Na segunda seção, na busca por um aporte talvez até mais metodológico, tivemos como referência principal os estudos semioliguísticos de Patrick Charaudeau (2008; 2012). Em trabalho anterior, aplicamos as abordagens do autor francês na leitura de telejornais (BRAIGHI, 2013), aproveitando-nos inclusive de um referencial que advinha de outros pesquisadores brasileiros com mais expertise (DAVID-SILVA, 2005) e das próprias investidas de Charaudeau nesse sentido. Na tese, no entanto, colocamos à prova reflexões e esquemas clássicos do pesquisador francófono para verificar não só as particularidades do Midiativismo, mas a utilização da Internet como suporte para a difusão das transmissões dos coletivos do gênero.

É buscando, no suporte da Análise do Discurso (mais especificamente da Semiolinguística), que tentamos inter-relacionar perspectivas da linguística com os fenômenos contemporâneos, das ruas e das redes, solidificando alguma base teórica para que, a partir disso, fosse elaborada uma metodologia que permitisse uma análise particular do objeto de pesquisa.

A partir do início do mês de junho de 2013, o Mídia Ninja passou a ganhar um sem-número de seguidores que, paulatinamente, acompanhava as transmissões do coletivo pela web. Mas, por quê? Indagou-se que essa questão poderia ser respondida no bojo das discussões relacionadas à metáfora do contrato de comunicação. Nesse sentido, de saída, começamos a debater sobre cláusulas e de que forma o cumprimento destas dão manutenção aos diálogos regulares - a partir de quais processos de (pré)validação. Seguiu-se com uma adaptação da lógica da maquinaria midiática de Charaudeau (2012), tragando-a para uma reflexão sobre a dinâmica do coletivo em análise, desaguando, de forma até ensaística, em posições acerca da informação como discurso e os desafios do midiativismo nesta senda. 


\section{METODOLOGIA}

A perna discursiva da fundamentação ancorou largamente a metodologia. No entanto, a primeira frente de observação parecia seguir um caminho um tanto diverso; considerou-se importante analisar o dispositivo técnico do Mídia Ninja ${ }^{4}$, numa cadência menos linguística e mais do campo das Exatas. Para empreender um processo comunicativo com os interlocutores, o coletivo faz uso de mecanismos, já que a relação não é direta; isto é, as partes estando distantes, necessitam de plataformas que suportem as trocas. O enunciador vale-se, então, da Internet como sustentáculo do trabalho dele, utilizando-se, de modo mais específico, de sites e perfis em redes sociais on-line. Para a tese, observou-se mais diretamente a aplicação do Twitcasting (plataforma para transmissão de vídeos em tempo real $)^{5}$, além de particularidades dos aparelhos utilizados para as coberturas e em como esses interferem nos modos de produção e recepção.

A seguir, na apreciação do dispositivo comunicacional e enunciativo midiativista, fora dividida a análise em seis dimensões distintas:

a) "dimensão contextual", que deu conta dos dados externos do contrato comunicativo - das identidades -, descrição dos participantes da cena comunicativa; finalidades (visadas); propósitos e condições dos contextos de transmissão (CHARAUDEAU, 2012);

b) “dimensão verbal-enunciva-enunciativa”, que reuniu a verificação, a partir dos dados internos do contrato comunicativo, como os enunciados são apresentados pelos repórteres Ninjas ao observarmos a análise das modalizações nos atos locutivos (alocuções, elocuções e delocuções) e nos modos de organização do discurso (enunciativo, descritivo, narrativo e argumentativo) - em esquemas adaptados de apreciação crítica (CHARAUDEAU, 2008);

c) “dimensão visual”, num espaço que reuniu elementos que evidenciaram como é mostrado, a partir do reconhecimento de perspectivas de indicialidade, da capacidade de descrição (identificação e qualificação) e do potencial simbólico - localizando o exame

\footnotetext{
${ }^{4}$ Ratificando que tomamos esse coletivo como referência em nossa análise.

${ }^{5}$ Hoje se observa a utilização do Facebook como plataforma principal por parte do Mídia Ninja para a transmissão simultânea. Em 2014, porém, tal rede social on-line não dispunha de tal funcionalidade.
} 


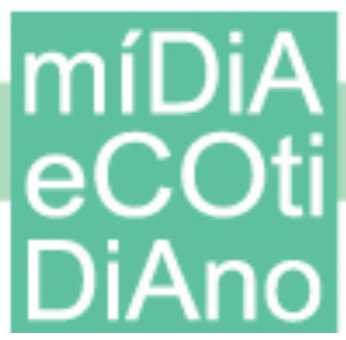

nas contribuições de Jost (1999) e Hanot (2001) e na apropriação de pesquisadores como David-Silva (2005);

d) "dimensão sonora", que sintetizou a questão dos ruídos que compõem as cenas locutivas além das nuances de locução dos Ninjas, em uma reflexão bem ensaística;

e) "dimensão imagem-texto", que é onde foi possível enxergar as possibilidades de intrincação do verbal com o visual, por meio das ancoragens (verbal sobre o visual) e do relais (visual como complementação) - tanto quanto as ausências possíveis (BARTHES, 1964);

f) e, “dimensão dos efeitos”, que é a seção pela qual as outras dimensões passam e se veem afetadas na medida em que são elas que parecem constituir esse espaço (CHARAUDEAU, 2012; DAVID-SILVA, 2005).

Por fim, o trabalho ainda se dedicou à análise interacional do Mídia Ninja com os seus respectivos interlocutores. Tal perspectiva foi entendida na tese como um processo que tem como suporte e fim as trocas comunicativas, autoinfluenciadoras, carregadas de significados, realizadas entre duas ou mais instâncias. Nesse sentido, buscou-se compreender esse artifício por meio das perspectivas do interacionismo simbólico e das práticas conversacionais (KERBRAT-ORECCHIONI, 2006).

Pensou-se que a fundamentação em Kerbrat-Orecchioni (2006) seria viável, devido à amplitude de suas propostas e à nossa filiação ao campo da linguística. Além disso, não é difícil verificar autores que relacionam a análise das dinâmicas interacionais on-line com as práticas conversacionais. Recorreu-se primeiro então a esses, no rastro das reflexões ora realizadas, para aproveitar a lógica da conversação já aplicada, em detrimento de uma releitura para gerar um novo modelo, senão uma forma mais completa de análise a partir da interseção de três abordagens que entendíamos complementares: Michel Marcoccia (2004), Amossy (2011) e Marques (2011) 6 .

\section{RESULTADOS E CONSIDERAÇÕES}

A cobertura midiativista paralela à Copa do Mundo colocou várias questões, entre elas: que valor tem o gozo do gol nas arenas futebolísticas frente às mortes nas favelas, à

\footnotetext{
${ }^{6}$ Além disso, foi preciso buscar alguns autores para a discussão sobre a interação multimodal, dado o tipo de relação entre os Ninjas e a audiência (KRESS, VAN LEEUWEN, 2001).
} 


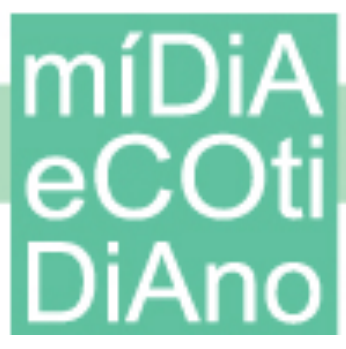

ausência de teto dos trabalhadores - que despendem valores incoerentes ao que recebem de transporte coletivo -, às agressões físicas e psicológicas das minorias, à estigmatização, à ausência de voz, à marginalização que o centro imputa? Como se sabe que essa realidade existe? Em verdade por uma série de fontes. Mas uma delas martela, insiste, persiste, entra em luta simbólica, na guerrilha de sentidos, arrostando com as suas armas, nada frágeis, mas localizadas, pontuais: o Midiativismo.

Um ano depois das manifestações que sacudiram o Brasil, o Mídia Ninja estava lá. Mas não jazia toda a gente. Havia, pois, certa multidão - mesmo aquela da fundamentação teórica -, que não é de quantidade, mas de personalidade. Resiliente, envolvida e engajada. Esse renque pôs-se a obrar e viu-se potencializado nas lentes dos coletivos; isso é, no ecrã dos monitores de quem não estava lá - ou estava?

Outra vez o Mídia Ninja serviu de ponte, de intercessão, de mecanismo de mostração dos acontecimentos em curso, no fluxo, evidenciando o que aparece, o mais próximo do que parece - semelha. Um coletivo que deu voz, que problematizou, que pôde ter servido até de ferramenta para trabalho crítico. Mas, toou muito a captação pela afetação de alguns eventos narrados.

Quem não foi às ruas, não se sabe se optou por conferir os registros. Quem foi, pudera, registrou; qualquer um o pode e pôde. Tem-se o reflexo de uma mídia então que se aproxima do jeito de fazer da audiência, da forma como qualquer sujeito o faz, hoje, se quiser, se interessa tornar-se midiativista. Não há segredos. Há disposição. O que as imagens revelam não é um estar ali para, mas estar por. Mídia multidão, bancada menos por um veículo (talvez pelo efeito de sentido de sua marca) e mais pelo sujeito que porta a mídia. Ninja é uma chancela que apenas rotula um coletivo, que atesta aquilo que um grupo faz e pode ser feito, afinal, por qualquer um - que seja ativo, ativista e medeie.

Não sem motivos a dificuldade de encontrar um padrão; cada Ninja acaba por agir de um jeito. É bem verdade que o coletivo é seu dispositivo, seu balcão (o que alça) e limitador, e não se pode esquecer que é a rubrica do veículo que, de forma primária, traz a audiência. Ainda assim, vimos variações que correspondem a uma ausência de explicação, senão as contextuais, do dia, de momento, de sensação mais do que intento.

Tem-se uma liberdade condicionada pela situação a ser enquadrada, pelo estado de espírito do midiativista, pela filosofia e até direcionamentos de quem sustenta a marca; 


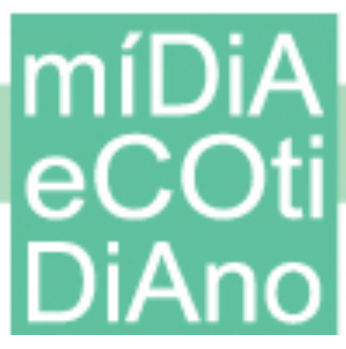

é perceptível nas transmissões que as orientações (ainda que não se fale em normas de conduta, mas em modo reflexivo) influenciem numa maneira de agir.

No entanto, a impressão que temos é que o acordo subscrito pelo Mídia Ninja com a audiência é maior do que o contrato comunicativo, ainda que influenciando-o. Talvez tenha sido até pacto, não assinado - mas cativado - em certa altura, influenciado por uma intensa carga subjetiva que dispensava no coletivo todo um conjunto de desejos, de orexia por representação, da carência por heróis, mártires, de sujeitos sem vínculos com a política partidária praticada no país. O Mídia Ninja não poderia cumprir tal ideia, posto que quem conseguiria?

Seguindo, numa aposta muito particular da tese, dissemos que é o Midiativismo (conceito) que decorre da ação (de um) midiativista, e não o contrário; tampouco o sujeito ativista com mídia faz-se pelo direcionamento de qualquer instituição, grupo ou coletivo. O comportamento é (deve ser) de deliberação própria. A vontade solidária que o indivíduo porta deve corresponder (muito) menos a ele, ou à marca que o sustenta (no sentido de suporte), e muito mais ao outro, ao bem comum.

É nesse sentido que também podemos dizer que a possibilidade midiativista é resignificada a cada nova transmissão. A chamada cobertura do Mídia Ninja converte-se em registro de Filipe, Letícia, Alex, e tantos outros, tão logo o streaming acenda. Um novo contrato, ou um acordo pautado sob as cláusulas já mais ou menos dadas pelo coletivo, é assinado naquele conjunto de lives.

Nesse contexto, diz-se de uma possibilidade midiativista, pois nem todas as transmissões o são. Muitas vezes a ação direta, clara, parece correr fora do comportamento de alguns integrantes do coletivo. Mas, o que há de transgressivo em compreender a marcha e ir tocando, junto, em frente? É aí que nasce a problemática da linha tênue entre o midialivrismo e o Midiativismo.

Senão em comportamentos extremos, como o de um Ninja a encarar e questionar a polícia - a sofrer, na pele, as consequências -, o que mais há de ativista no comportamento deles? Compreendemos que, em primeiro lugar, o estabelecimento de uma narrativa específica, em primeira pessoa, sem edições, em e no fluxo dos acontecimentos, gerando um registro diferente daquele que se têm nos media, a partir de 


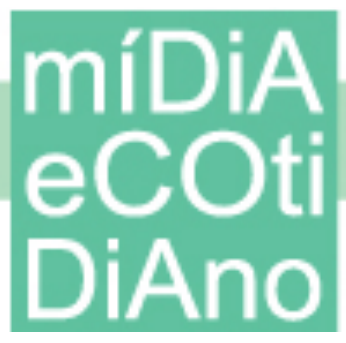

um movimento de experimentação evenemencial e que se posiciona claramente ao lado (físico e moral/ideal) de uma das partes em disputa, configuraria mais o midialivrismo.

Porém, observemos a expressão "movimento de experimentação evenemencial"; o que é importante assinalar é que o Midiativismo não se trata de uma vivência passiva, mas na intervenção que gera (ou pretende) mudança, trazer o novo, a partir de cinco marcas que são facilitadas pelo uso de dispositivos técnicos - e sua manipulação com intentos claros, a saber, conforme já colocado antes: amplificar conhecimento, espraiar informação, marcar presença, empreender resistência e estabelecer estruturas de defesa.

Senão de forma totalizante (as cinco frentes simultaneamente), conjecturamos que o Mídia Ninja, por meio do trabalho dos midiativistas, alcançou tal intento. Tais vetorizações foram perceptíveis em quase todas as abordagens no recorte, conformando um modo específico de ação direta midiática, que, pelas características, estabelecem relação muito próxima com o exercício de manifesto dos sujeitos aos quais deram voz.

Acredita-se, assim, com todo o conjunto de dados da tese, que o lugar que o grupo ocupa no regime discursivo midiático atual é o da contrainformação, o da problematização, do posicionamento à margem e o da ausência de moldes e modelos estanques de atuação - a subverter os conhecimentos que, inclusive, detêm de um modo produtivo e estético tradicional das mídias (TV, cinema, artes).

O lugar do Mídia Ninja (e dos midiativistas) não parece ser um ponto fixo, tampouco está em porto seguro. Aliás, indica ser isso mesmo, nada contraditoriamente, o que procura. O coletivo nasce com fidúcias, mas cresce com apenas uma certeza: sua efemeridade. Na condição de midialivrista, quer quebrar a ideia do sistema de comunicação que se tem hoje, com a dominação dos espectros de radiofrequência, que instala uma ditadura midiática estruturada em oligarquias de poder. O que se visa é a democratização, um sistema sem regulamentos, mais colaborativo, ao mesmo passo participativo e que permita, inclusive, que o ativismo midiático se faça cada vez menos presente na medida em que se dê a existência de um regime linear, em que as vozes sejam ouvidas, que as ideias sejam respeitadas, as causas debatidas e, quiçá, resolvidas.

Nesse contexto, o espaço do Mídia Ninja e dos coletivos midiativistas no chamado regime midiático é intrusivo (não devia estar ali), visando ser diruptivo. Vivemos tempos incertos em relação à hegemonia de um sistema de significação, muito 
em razão das possibilidades e potencialidades da web. Não precisamos nem lembrar que o conjunto de regras e o padrão cartesiano, que se encontra na produção da informação midiática, se vê ainda em xeque diante das arestas perceptíveis no modelo industrial dos media, revelando problemas para a sustentação dos grandes grupos jornalísticos.

Mas a questão aqui não é essa última; queremos destacar que o Mídia Ninja e o Midiativismo de 2014, certamente não são os mesmos de hoje, 2017 - e poderíamos esboçar o planejamento para outra tese, no sentido de compreender esse Mídia Ninja e o Mdiativismo atual; porém, seria inválido, senão para demonstrar como o cenário político (social, cultural, econômico) brasileiro interferiu em um modo de articulação desse coletivo e dessas investidas. Diante dos contextos e da liquidez da sociedade contemporânea, ele e as outras iniciativas midiativistas devem reconformar-se, reconstruir-se, reinventar-se, continuando o exercício cíclico da experimentação que vêm articulando. Nossa pesquisa, todavia, não perde o valor, pois acentua o registro temporal e o comportamento midiativista, importante, que se encontrou em um lugar marcante da história.

O regime midiático contemporâneo, como conjunto de normas fixas, então, cada vez mais tem se tornado a ausência delas, conformando um sistema de redes no qual qualquer um pode hoje intervir com uma produção própria. O Mídia Ninja e os seus colaboradores souberam mobilizar sentidos nesse contexto, conseguiram manipular traçados e estabelecer novas linhas de significação, colocando na web (na rede e aos enredados) quem lá não estava - ainda que, desde muito tempo, afetado por ela.

Outro problema que se coloca, outrora, é a direção da recepção; muitos sujeitos na Internet ainda não se deram conta do potencial da grande rede e repetem, em geral, o mesmo procedimento que têm na leitura das mídias off-line. Não estamos, assim, colocando o Mídia Ninja e o Midiativismo em um pedestal. Apenas destacamos que a leitura da produção de coletivos do gênero tem condição de ampliar o cabedal de informações dos sujeitos, potencializando a produção de conhecimento a partir de um comportamento crítico acerca dos acontecimentos e da sociedade em que estamos inseridos. Para tanto, é preciso que o peixe seja fisgado, mas não fique preso a apenas uma rede. Vale lembrar que o Mídia Ninja não evidencia o que aparece; antes, na transmissão do coletivo aparece o que se evidencia, o que se quer mostrar, dentro de uma 


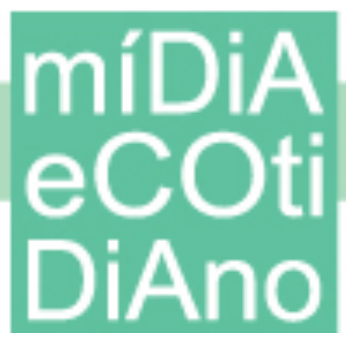

parcialidade localizada. Ficamos, no regime Ninja, com parte da história, com uma versão da verdade, construída em torno de maneiras de organização do discurso bem marcadas.

Chegamos a tais considerações no curso de nossos resultados, afiançados pela metodologia escolhida e aplicada; dividida em dimensões, tivemos, por exemplo, uma longa seção de apreciação crítica. Verificamos nessa primeira perna a profusão de identidades que orbitam em uma transmissão, a heterogeneidade do público - e seu interesse evenemencial -, os comportamentos variantes do midiativista em razão dos papéis que assume e que as características pessoais (EUc) parecem influenciar muito no modo de condução dos enunciadores (EUe) - em detrimento até da possível orientação do coletivo; as finalidades do ato comunicativo, percebendo que a questão não se fecha apenas no fazer-saber, mas envolve uma série de outras visadas, em profusão, em movimento, chocando-se, repelindo-se e/ou imbricando-se; que as ruas são os cenários preferenciais de atuação dos Ninjas e por quê; que, no propósito, os motes de maior repercussão têm certo direcionamento de noticiabilidade - em temas que são em verdade norteados por um intento de alerta e problematização.

$\mathrm{Na}$ segunda perna, a da dimensão verbal-enunciva-enunciativa, percebemos estratégias tênues de modalização dos textos verbais por parte dos Ninjas, captando a atenção (e amalgamando suavemente efeitos) do webespectador, ora com uma postura alocutiva, outra elocutiva e até delocutiva. A variação é a regra. Isso tanto quanto na dinâmica narrativa e argumentativa, revezando-se, a depender, como já colocamos, do Ninja, das situações de contexto e das finalidades em cada evento narrado.

A análise desse dispositivo seguiu com uma apreciação da dimensão visual do Mídia Ninja, em que procurou-se evidenciar vários aspectos de um amplo esquema. Foram trazidos à baila diversos feitios, que demonstram a plástica do coletivo, à luz da dinâmica evenemencial e, muitas vezes, de um comportamento pouco cartesiano quando não estratégico -, numa particularidade técnica que lhe dá distinção.

Em seguida, embrenhou-se em outra frente de apreciação crítica, nova, sem fundamentação que pudesse auxiliar: a análise sonora. Os dados, ainda que seguindo uma estrutura ensaística e numa interpretação muito particular do analista, não negam a importância de tal frente. Os ruídos, por exemplo, são determinantes no modo de produção e de recepção das transmissões do Mídia Ninja, por (e)feitos diversos. 
Reivindicaram-se as considerações de Barthes para a análise de intercessão imagem + texto. Aliás, somaram-se às duas perspectivas colocadas pelo semiólogo francês os vácuos, numa condição de (limitação) técnica do Mídia Ninja. Ali, viram-se uma série de efeitos de sentidos carregados pela potencialidade audiovisual e em como as características desse composto afetam o ato de linguagem do coletivo/midiativista com o público. Não sem motivos, essa intercessão encaminhou a discussão para a perna final deste objetivo: o exame dos efeitos como dimensão discursiva.

Vê-se que os Ninjas se utilizam (não se afirma a intencionalidade) de uma série de estratégias discursivas que fazem emergir as perspectivas dos efeitos de realidade, ficção e patemização, com capacidade, por isso, de afetar os webespectadores (não afiançando que as decorrências sejam efetivamente produzidas) de diversas formas. Percebe-se, ao final, uma nada tênue inter-relação entre os efeitos na condução Ninja, fruto, muito provavelmente, da própria lógica de hibridização mídia + ativismo. Ao passo que o coletivo é fundamentalmente da ordem da informação e que, por isso mesmo, faça recorrência às perspectivas de realidade de forma recursiva, é outrora eminentemente compassivo e passional, posto que as transmissões referem-se a eventos que têm como norte mudanças no tecido social que, se efetivamente alcançadas, dirão respeito à vida de integrantes de diversos grupos sociais, inclusive, desses repórteres.

O terceiro objetivo foi o da análise da dinâmica interacional do Mídia Ninja com os receptores/interlocutores na plataforma Twitcasting, a partir do exame das trocas realizadas a partir dos chats. Acredita-se que a apreciação alcançou o pretendido, levantando problemas e peculiaridades diversas de uma relação que, por vezes, é de força e em outros momentos de colaboração com o midiativista em campo: Na possibilidade de (re)validação dos contratos entre audiência e coletivo; oportunizando voz a outros excluídos - às pessoas comuns na rede; e, acima de tudo, conformando uma narrativa paralela, que influencia naquela articulada pelo Ninja e afetando no modo de edificação dos sentidos sobre o que se evidencia na transmissão.

Mais do que isso, a interação na plataforma, condiciona a criação de uma rede social efêmera, ágora passageira, na qual não há como avaliar os resultados, senão assinalar a contribuição para a circulação de saberes dos mais distintos. O espaço, em relação direta com os eventos em curso, no tomar de vozes diversificadas, na disputa, nas 
trocas nem sempre gentis, vão colocando em discussão temas que são contemporâneos e fundamentais. Experiencia-se uma prática dialógica nova, multimodal muitas vezes, que auxilia na conformação de pontos de vista, na subjetivação cooperativa, numa conversação que se estende pelas redes e pelas ruas.

O objetivo específico que nos faltou falar aqui foi o técnico. Percebemos que os equipamentos, a plataforma e outros aparatos que fazem parte do sistema de produção e recepção das transmissões têm faculdade de influenciar (projetando ou limitando) nos processos de significação. Para tanto, evidenciamos todas as características ligadas ao modo fabril Ninja/midiativista.

Acreditamos que nossa tese traz certa luz sobre o Midiativismo. Se não explica por completo, ao menos auxilia em certa sedimentação dos caminhos para se pensar com mais fundamentação, menos achismos, de modo mais crítico e, de certa forma, até com mais respeito acerca de tal fenômeno. Almejamos ter contribuído socialmente, então, já que houve um comprometimento acadêmico que visou decompor de forma incisiva e criteriosa a produção de um coletivo que, para um significativo número de pessoas, foi eleito como baluarte da mediação, o representante de informação evenemencial (e até de atuação nas ruas). Assim, entendê-lo, de certo modo foi compreender um pouco (ou uma parte) de nossa sociedade, seus interesses, seus medos, suas necessidades e desejos. Um fragmento de coletividade que se cansou de versões sobre os fatos (calçadas em interesses diversos, distantes do comum) colocadas com o discurso de imparcialidade, se enfastiou de ver e ouvir os mesmos sustentáculos de arquétipos, se aborreceu com estereótipos e de saber que tantas vozes, causas e pontos de vista são aplacados tão-somente por serem ordinários, comuns.

Sociedade, entretanto, que deve se atentar para não cair em uma (re)alienação com ares de libertação. E, nesse contexto, nosso trabalho coopera ao enxergar o Mídia Ninja (e o próprio Midiativismo) como uma fonte importante de conhecimento, sim, mas que guarda muitas particularidades que são determinantes ao tipo de produção que articula. $O$ futuro é incerto e se vê complexificado por cenários políticos problemáticos no Brasil e, eles também, influenciam no redirecionamento do comportamento midiativista em geral. Estrutura e investimento de atenção e tempo que correspondem exatamente à mudança 
social que se aguarda no país. Como e onde ela será feita são questões por demais complexas. Quando, parece ser mais fácil: no momento mesmo dessa leitura.

\section{Referências}

AMOSSY, R. O intercâmbio polêmico em fóruns de discussão online. Comunicação e Sociedade, Braga (Portugal), v. 16, p. 67-83, 2009.

ATTON, C. Approaching alternative media. Scotland: Napier University, 2001.

BARTHES, R. Rhetorique de l'image. Communications, Paris: Seuil, n. 4, 1964.

BENTES, I. Mídia-Multidão: estéticas da comunicação e biopolíticas. Rio de Janeiro: Mauad X, 2015.

BRAGA, J. L. Sobre mediatização como processo interacional de referência. In: ENCONTRO ANUAL DA COMPÓS, 15., 2006, Bauru (SP). Anais... Bauru (SP), 2006.

BRAIGHI, A. A. Análise de telejornais. Rio de Janeiro: E-papers, 2013.

. Análise do Discurso Midiativista: Uma abordagem às transmissões simultâneas do

Mídia Ninja. Tese (Doutorado em Letras) - Faculdade de Letras, UFMG, Belo Horizonte, 2016. .; CÂMARA, M. T. O que é Midiativismo? Uma proposta conceitual. In: BRAIGHI, A. A.; LESSA, C.; CÂMARA, M. T. Interfaces do Midiativismo: do conceito à prática. (no prelo). CEFET-MG: Belo Horizonte, 2018.

.; EMEDIATO, W.; ANTUNES, E. O jornalismo de guerrilha e o Mídia Ninja. In: EMEDIATO, Wander (Org). Análises do Discurso Político. 1ed.Belo Horizonte: FALE UFMG, 2016.

CARTA Mundial da Mídia Livre. In: FÓRUM MUNDIAL DAS MÍDIAS LIVRES, 5., mar. 2015, Túnis. Disponível em: <http://goo.gl/RC5stK>. Acesso em: 16 nov. 2015.

CASTELLS, M. A era da informação. São Paulo: Paz e terra, 1999.

Zahar, 2013.

Redes de indignação e esperança: movimentos sociais na internet. Rio de Janeiro:

CHARAUDEAU, P. Discurso das mídias. São Paulo: Contexto, 2012.

Linguagem e discurso. Modos de organização. São Paulo: Contexto, 2008.

DAVID-SILVA, G. A informação televisiva: uma encenação da realidade. 2005. 219 f. Tese (Doutorado em Letras) - Faculdade de Letras, UFMG, Belo Horizonte, 2005.

DOWNING, J. D. H. Mídia radical: rebeldia nas comunicações e movimentos sociais. 2. ed. São Paulo: SENAC São Paulo, 2004.

FAUSTO-NETO, A. Fragmentos de uma analítica da midiatização. Revista Matrizes, São Paulo, v. 1, n. 2, p. 89-105, abr. 2008.

GOMES, P. G. Filosofia e ética da comunicação na midiatização da sociedade. São Leopoldo (RS): Unisinos, 2006.

HANOT, M. Télevision-realité ou réalisme? Bruxelles: De Boeck Université, 2002.

HARDT, M.; NEGRI, A. Multitude: War and democracy in the age of empire. Nova York: Penguin Books, 2005.

JORDAN, T. Activism! Direct action, hacktivism and th future of society. London: Reaktion Books, 2002.

JOST, F. Introduction à l'analyse de la television. Paris: Elypses Ed. Marketing, 1999.

KERBRAT-ORECCHIONI, C. Análise da conversação: princípios e métodos. São Paulo: Parábola, 2006.

KRESS, G.; VAN LEEUWEN, T. Multimodal discourse. London: Bloomsbury Acad., 2001

LÉVY, P. O que é o virtual? São Paulo: Editora 34, 2003.

MALINI, F.; ANTOUN, H. A internet e a rua: ciberativismo e mobilização nas redes sociais. Porto Alegre: Sulina, 2013. 
MARCOCCIA, M. L'analyse conversationnelle des forums de discussion: questionnements méthodologiques. Les Carnets du Cediscor, v. 8, p. 23-37, 2004.

MARICATO, E. et al. (Org.). Cidades rebeldes: passe livre e as manifestações que tomaram as ruas do Brasil. São Paulo: Boitempo/Carta Maior, 2013.

MARQUES, A. Aspectos teórico-metodológicos do processo comunicativo de deliberação online. Revista Brasileira de Ciência Política, Brasília, n. 6, p. 19-40, jul./dez. 2011.

RAMONET, I. A explosão do jornalismo na era digital. In: MORAES, D.; RAMONET, I.; SERRANO, P. (Orgs.). Mídia, poder e contrapoder - da concentração monopólica à democratização da comunicação. Boi Tempo Editorial: São Paulo, 2013. p. 73-86.

RENDEIRO, M. F. Defining alternativess: the meaning alternative journalists give to their work. Amsterdam: Universiteit van Amsterdam, 2003.

RICCI, R.; ARLEY, P. (fotos). Nas ruas. A outra política que emergiu em Junho de 2013. Belo Horizonte: Editora Letramento, 2014.

RODRIGUES, A. D. A gênese do campo dos media. In: SANTANA, R. N. Monteiro (Org.) Reflexões sobre o mundo contemporâneo. Rio de Janeiro: Revan, 2000. p. 201-210.

SODRÉ, M. Antropológica do espelho. Petrópolis: Vozes, 2004.

TORET, J. Tecnopolítica: La potencia de las multitudes conectadas. El sistema red 15M. Informe de Investigação, Barcelona, v. 1, n. p., 2013. 